\title{
Bedload flux in southern Brazilian basalt scarp
}

\author{
GUSTAVO HENRIQUE MERTEN ${ }^{1}$ \& JEAN PAOLO GOMES MINELLA ${ }^{2}$ \\ 1 Visiting Research Professor, Department of Civil Engineering, University of Minnesota, Minnesota, USA \\ mertengh@gmail.com \\ 2 Department of Soils, Federal University of Santa Maria, 97105-900, Santa Maria, Brazil
}

\begin{abstract}
Frequently, to assess the life expectancy of Brazilian reservoirs, bedload flux has been estimated by using formulas (e.g. the Einstein equations) or by assuming that bedload represents a fixed percentage of the suspended load. This study was carried out to characterize the bedload flux on the basalt scarps of southern Brazil. The bedload was measured over the course of 12 stormflows. The results demonstrated that the bedload flux-streamflow relationship was adequately described by a potential mathematical function. Bedload flux selectively transported particles smaller than $\mathrm{D}_{50}$ surface and subsurface bedstream sediments. When considering the bedload flux-streamflow relationship, the flux ranged from a minimum of $0.24 \mathrm{~g} \mathrm{~m}^{-1} \mathrm{~s}^{-1}$ for a streamflow of $0.53 \mathrm{~m}^{3} \mathrm{~s}^{-1}$ to a maximum of $44 \mathrm{~g} \mathrm{~m}^{-1} \mathrm{~s}^{-1}$ for a streamflow of $1.3 \mathrm{~m}^{3} \mathrm{~s}^{-1}$. The percentage of bedload/suspended load varied between $<1 \%$ up to $60 \%$, and this variation was strongly associated with peak flow.
\end{abstract}

Key words bedload, step-pool streams; Maddock classification; reservoir life expectancy; Brazilian basalt scarps; hydropower

\section{INTRODUCTION}

In Brazil, $85 \%$ of electricity is generated by hydroelectric dams installed primarily in the southcentral region of the country, although several new dams are currently under construction in the Northern region as well (ANEEL, 2014). In the south of Brazil, especially in the region of basalt scarps where the topography is rolling, many small dams with capacities of less than $30 \mathrm{MW}$ are being constructed. The success of these projects depends on the estimated useful life of the reservoirs, especially since this region is heavily utilized for agriculture, generating a large supply of sediments (>100 t km year $^{-1}$; Merten et al., 2010). In Brazil, as with most countries of South America, little information is available about suspended sediment flux, especially for smaller rivers. Information about bedload flux is extremely rare, and when it does exist, is limited to a few case studies (Cantalice et al., 2014).

In general, sediments smaller than $1 / 8 \mathrm{~mm}$ are transported in suspension. Sediments larger than $8 \mathrm{~mm}$ are transported as bedload, and intermediate sizes are transported either in suspension or with the bedload, depending on hydrodynamics of the streamflow conditions and sediment particle size (Wilcock et al., 2009). Difficulties with measuring bedload are related to the enormous spatial-temporal variability of sediment flux (Wathen et al., 1995), attributable to factors such as the presence of dunes, localized changes in streamflow shear stress $(\tau)$, fluctuations in turbulence, variations in upstream sediment supply, and changes in particle size of sediments on the surface of the river bed (Diplas et al., 2008).

In the absence of bedload measurements, formulas such as the Einstein or Colby equations have been used, or an assumption is made that bedload represents a certain percentage of the suspended sediment load. Carvalho et al. (2000) note that it has been common in Brazil to arbitrarily assign $10 \%$ of the total sediment load as bedload. It has also been common in Brazil to use the Maddock classification to estimate bedload (Lane \& Borland, 1951; Vanoni, 2006; Garcia, 2008). The Maddock classification estimates bedload using parameters such as suspended sediment concentration (SSC), texture of suspended material, and characteristics of river bed material.

The theoretical basis of the Maddock classification rests on four principles (Lane \& Borland, 1951): (a) the lower the suspended sediment concentration, the higher the percentage of bedload; (b) the smaller the difference in particle size between the bedload material and the suspended load material, the higher the percentage of the bedload to the total load; (c) streams with shallow channels carry a higher proportion of sediment as bedload when compared with deep, narrow channels; and (d) streams with a high degree of turbulence tend to transport a higher proportion of 
sediment in suspension. The Maddock classification should be considered an approximate method to estimate bedload and, whenever possible, bedload should be measured using appropriate equipment (Garde \& Ranja Raju, 1977). Studies measuring the proportion of bedload to suspended sediment load have shown that this can range from 5 to $30 \%$ for low gradient rivers, and from 10 to $90 \%$ for high gradient rivers (Lenzi et al., 2003; Cantalice et al., 2014).

Steep streams in the basalt scarps of southern Brazil have a primarily step-pool morphology. These rivers are very stable as much of their streamflow energy is dissipated by elements such as boulders and step-pools (Whittaker, 1987). Sediment transport in these streams depends primarily on the availability of sediments, which originate from different sources such as hillslope erosion, landslides, debris flow and erosion of stream banks. Sediments in step-pool streams move mostly during high flow periods, while during the receding limb of the hydrograph the transported material is stored in the pools. This ability to store sediment in the pools as well as the armouring effect, which is common in this type of channel, cause complex hysteresis effects in the transport process and, as a result, in the way bedload transport can be represented through formulas (Whittaker, 1987).

This article seeks to characterize the bedload flux and the ratio of bedload to suspended load in a step-pool stream representative of the conditions on the basalt scarps of southern Brazil.

\section{THE ARVOREZINHA EXPERIMENTAL CATCHMENT}

\section{Catchment characteristics}

The Arvorezinha Experimental Catchment was established in 2001 and is located on the southern plateau of Brazil (28 $\left.49^{\prime} 30^{\prime \prime} \mathrm{W}, 52^{\circ} 12^{\prime} 29^{\prime \prime} \mathrm{S}\right)$ in the state of Rio Grande do Sul, in southern Brazil (Fig. 1). The catchment's drainage area is $1.2 \mathrm{~km}^{2}$ and land use is mainly tobacco fields and forest.

Annual precipitation varies between 1250 and $2000 \mathrm{~mm}$. The hydrologic regime is characterized by rapid response to precipitation events, with about 40 minutes to concentration time. Average flow is $0.050 \mathrm{~m}^{3} \mathrm{~s}^{-1}$, but it frequently reaches $1.0 \mathrm{~m}^{3} \mathrm{~s}^{-1}$, with the greatest measured value over a 10 year period of $6 \mathrm{~m}^{3} \mathrm{~s}^{-1}$. The catchment is underlain by acid volcanic rocks (Rhyodacite) and the highly erodible nature of these rocks has resulted in terrain characterized by steep slopes and deep, narrow valleys. The local topography is characterized by three distinct zones. In the lower third of the basin, the hillslopes are short and steep (100-250 $\mathrm{m}$ and 20-30 slope) and the valley bottoms are narrow $(2-5 \mathrm{~m})$. In contrast, in the upper third of the basin, the

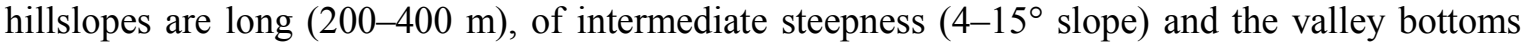
broader $(10-15 \mathrm{~m})$. In the middle third of the basin, the upper slopes are relatively gentle, but the slopes steepen further downslope towards the stream channels, resulting in slopes with convex profiles. The valley bottoms are narrow (5-30 $\mathrm{m}$ in width). Due to the local geological conditions, the channel network is characterized by step-pool channels with high roughness and turbulent flow (Fig. 2). The average channel gradient is $0.09 \mathrm{~m} \mathrm{~m}^{-1}$ and the flow is strongly influenced by the presence of bed material with a diameter greater than $256 \mathrm{~mm}$ (pebbles and boulders).

\section{Monitoring}

Streamflow (Q) was determined by continuous monitoring of the stage within a Parshall flume using a pressure sensor. A recording interval of 10 minutes was used and this provided adequate characterization of the rising limb. Suspended sediment concentration (SSC) monitoring was based on the manual collection of samples during flood events using a US-DH-48 sampler.

Suspended sediment load (mass per unit of time) was estimated by multiplying the instantaneous Q $\left(\mathrm{L} \mathrm{s}^{-1}\right)$ by the SSC $\left(\mathrm{g} \mathrm{L}^{-1}\right)$. Event sediment yields (SY) were estimated by integrating the suspended sediment flux over time (Walling \& Collins, 2000).

Bedload transport rate was measured on the 9th and 10th of July 2007; 22 July 2007; and 22 and 23 September 2007. Measurements were carried out using a US-BLH-84 pressure differential sampler with a $0.25 \mathrm{~mm}$ polyester mesh bag (Edwards \& Glysson, 1999). Samples were taken from the entrance of the Parshall flume where width was $2.5 \mathrm{~m}$. The sampling section was divided 


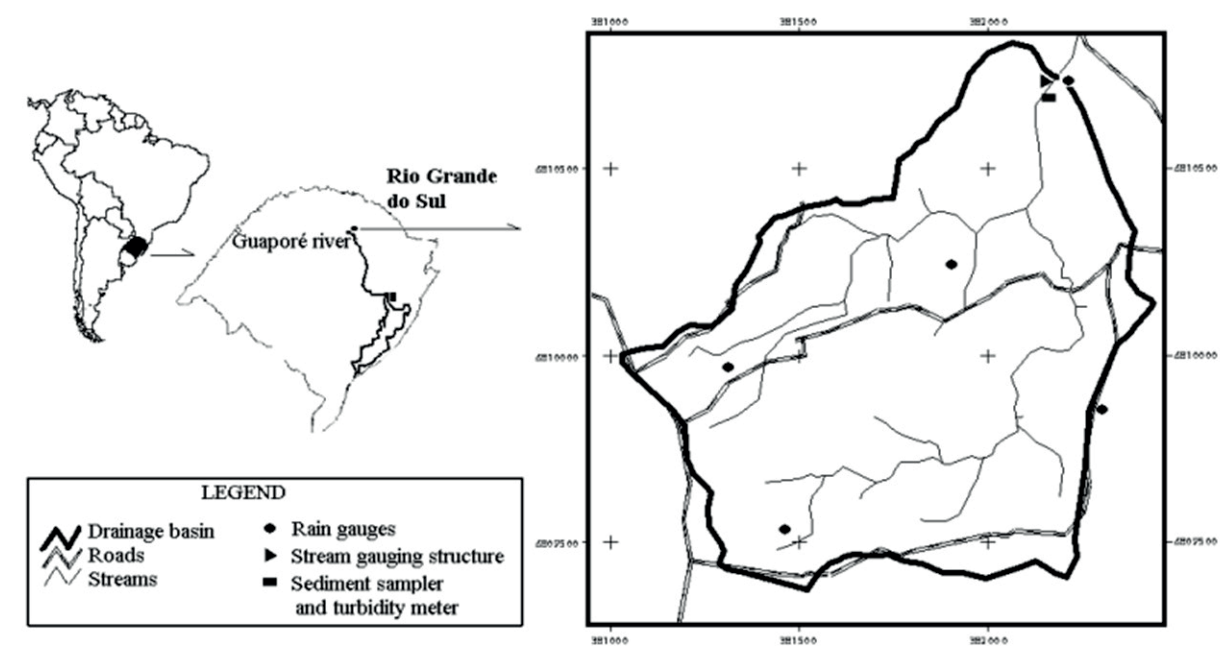

Fig. 1 The location of the Arvorezinha Experimental Catchment.

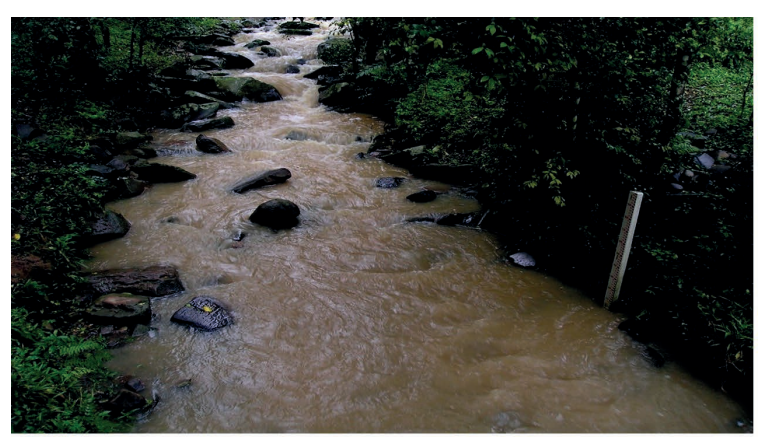

Fig. 2 Picture of the Arvorezinha Experimental Catchment step-pool stream channel.

into eight verticals and the collection time for each vertical was $30 \mathrm{~s}$. As such, for each sample associated with a streamflow, 40 sub-samples were collected, as recommended by Edward \& Glysson (1999).

To process the samples, organic matter was separated, dried and weighed. The calculation of the bedload transport rate was carried out according to equation (1). For each bed load transport rate (and associated Q value), the particle size of the sediment was characterized according to the $\mathrm{D}_{50}$ parameter.

$$
q_{\mathrm{sml}}=\frac{m}{w t}
$$

where: $q_{\mathrm{sml}}$ refers to the bedload transport rate $\left(\mathrm{g} \mathrm{s}^{-1} \mathrm{~m}^{-1}\right), m$ is the dry mass of the sediments collected over 40 measurements $(\mathrm{g}), w$ is the width at the mouth of the equipment $(\mathrm{m})$ and $t$ is the total sampling time for the 40 samples (s).

Sampling to characterize sediment particle size of the streambed was carried out using material collected from the surface and the substrate, as described by Bunte \& Abt (2001). The sampling site was determined randomly using a $0.36 \mathrm{~m}^{2}(0.6 \times 0.6 \mathrm{~m})$ frame to establish a standard representative area. The material within the frame was separated in two parts: material from the surface of the streambed and material from the substrate. After removing the surface material, the bottom was dug up and substrate material was collected to a depth of $0.10 \mathrm{~m}$. The material was then dried and analysed. For sediment greater than coarse gravel $(>16 \mathrm{~mm})$ a granulometer was used to measure the "b" axis of each particle. The material smaller than coarse gravel was sieved and a size-frequency distribution curve and $\mathrm{D}_{50}$ factor were generated.

To evaluate the relationship between bedload and suspended sediment load, 12 stormflows between 2002 and 2011 were selected, based on producing sufficient hydrodynamic conditions for bedload transport (water discharge $>0.40 \mathrm{~m}^{3} \mathrm{~s}^{-1}$ ). The bedload flux was estimated using stream 
flow Q collected at intervals of 10 minutes and the bed load rating curve (streamflow $v s$ bedload transport rate). The bedload sediment yield for each event was calculated adding the bedload sediment flux. This value was compared with suspended sediment yield.

\section{RESULTS AND DISCUSSION}

\section{Bedload transport rate}

Streamflow characteristics associated with different bedload transport rates are shown in Table 1. $\mathrm{Q}$ is shown to vary between 0.43 and $1.29 \mathrm{~m} \mathrm{~s}^{-1}$. The beginning of the bedload transport was identified at $>0.40 \mathrm{~m}^{3} \mathrm{~s}^{-1}$ which corresponds to a flow velocity of about $0.8 \mathrm{~m} \mathrm{~s}^{-1}$. The Froude number, Fr (relation between inertial forces and gravitational forces) indicates a subcritical streamflow condition for all the measurements. Step-pool channels are made up of a sequence of steps in which streamflow is accelerated (supercritical) over rock outcrops, while in the concave pools streamflow is subcritical (Curran, 2007). The bankful streamflow (the 2-year recurrence interval water discharge) has been estimated to be around $0.8 \mathrm{~m}^{3} \mathrm{~s}^{-1}$ (flow velocity approx. $1 \mathrm{~m} \mathrm{~s}^{-1}$ )

$\mathrm{D}_{50}$ values of the bedload transport rate in Table 1 vary between the different grain size fractions, from medium sand $(0.39 \mathrm{~mm})$ to very fine gravel $(4.36 \mathrm{~mm})$. These results indicate that the particle size of the transported material (Table 1) is smaller than the material found on the stream bed (Table 2). Figure 3 of the relation between $\mathrm{Q}$ and the $\mathrm{D}_{50}$ value shows that an increase in $\mathrm{Q}$ does not necessarily correspond to an increase in $\mathrm{D}_{50}$ 'values. These findings suggest that $\mathrm{Q}$ selectively transports particles that are smaller than the $\mathrm{D}_{50}$ value measured for the surface and subsurface of the stream bed (Table 2). Selective bedload transport has been also observed by others authors working with step-pool and gravel bed streams (Lisle, 1995; Pitclik et al., 2008). According with these authors, the mechanism related to selective transport is explained by the lateral and longitudinal sorting of bed material into patches that include fine material which are readily entrained and move rapidly downstream. Observations of the transport of cobbles and boulders in Arvorezinha stream catchment occur when $\mathrm{Q}$ is higher than $1.3 \mathrm{~m}^{3} \mathrm{~s}^{-1}$.

The bedload transport rating curve is shown in Fig. 4. According to this figure, the bedload transport rate for Q between 0.40 and $0.80 \mathrm{~m}^{3} \mathrm{~s}^{-1}$ was low $\left(0.73-3.15 \mathrm{~g} \mathrm{~s}^{-1} \mathrm{~m}^{-1}\right)$ however, for $\mathrm{Q}>$ $0.8 \mathrm{~m}^{3} \mathrm{~s}^{-1}$ the bedload transport rate increases exponentially. Power function rating curves

Table $1 \mathrm{Q}$, hydraulic characteristics, bed load transport rate, and D50 of the transported sediments.

\begin{tabular}{llllll}
\hline Date & $\begin{array}{l}\mathrm{Q} \\
\left(\mathrm{m}^{3} \mathrm{~s}^{-1}\right)\end{array}$ & $\begin{array}{l}\mathrm{v} \\
\left(\mathrm{m} \mathrm{s}^{-1}\right)\end{array}$ & Fr & $\begin{array}{l}\text { Bedload rate } \\
\left(\mathrm{g} \mathrm{m}^{-1} \mathrm{~s}^{-1}\right)\end{array}$ & $\begin{array}{l}\mathrm{D}_{50} \\
(\mathrm{~mm})\end{array}$ \\
\hline 9-Jul-07 & 0.43 & 0.80 & 0.58 & 0.73 & 0.48 \\
9-Jul-07 & 0.58 & 0.87 & 0.59 & 1.99 & 1.21 \\
10-Jul-07 & 0.59 & 0.88 & 0.59 & 0.54 & 1.16 \\
10-Jul-07 & 0.53 & 0.85 & 0.58 & 0.24 & 0.59 \\
22-Jul-07 & 0.71 & 0.93 & 0.59 & 1.79 & 0.39 \\
22-Jul-07 & 1.09 & 1.06 & 0.61 & 4.87 & 0.52 \\
22-Jul-07 & 0.80 & 0.96 & 0.60 & 3.15 & 0.87 \\
22-Sep-07 & 0.96 & 1.02 & 0.60 & 13.4 & 50.87 \\
22-Sep-07 & 1.23 & 1.10 & 0.61 & 18.8 & 10.89 \\
22-Sep-07 & 0.63 & 0.89 & 0.59 & 3.77 & 1.64 \\
23-Sep-07 & 1.29 & 1.12 & 0.62 & 44.4 & 22.36 \\
23-Sep-07 & 1.00 & 1.03 & 0.60 & 34.1 & 34.36 \\
\hline
\end{tabular}

$\mathrm{Q}$, streamflow $\left(\mathrm{m}^{3} \mathrm{~s}^{-1}\right)$; v, flow velocity $\left(\mathrm{m} \mathrm{s}^{-1}\right)$; Fr, Froude Number (dimensionless); $\mathrm{D}_{50}$, grain size sediment sampled (mm).

Table 2 Surface and subsurface values of the $\mathrm{D}_{90}, \mathrm{D}_{50}$ and $\mathrm{D}_{10}$ stream bed sediment classes.

\begin{tabular}{llll}
\hline Sediment class & $\mathrm{D}_{90}(\mathrm{~mm})$ & $\mathrm{D}_{50}(\mathrm{~mm})$ & $\mathrm{D}_{10}(\mathrm{~mm})$ \\
\hline Surface & $101.9($ cobble $)$ & 59.2 (very coarse gravel) & 40.7 (very coarse gravel) \\
Sub-surface & 29.4 (coarse gravel) & 10.2 (medium gravel) & 0.61 (coarse sand) \\
\hline
\end{tabular}




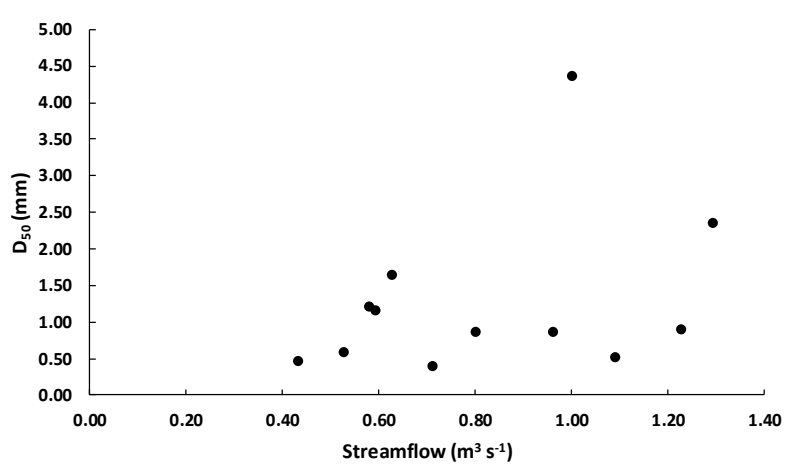

Fig. 3 Relation between streamflow and $\mathrm{D}_{50}$ particle size.

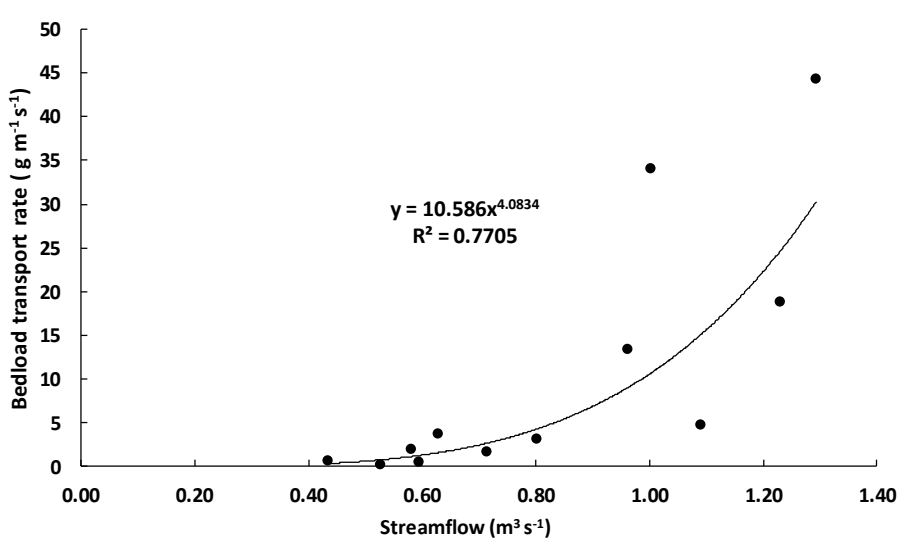

Fig. 4 Bedload transport rate and streamflow using a US BH-84 sediment sampler at Arvorezinha catchment.

have frequently been used to describe bedload transport rates as a function of Q. Exponents $\left(a Q^{b}\right)$ varying between 5 and 20 have been found by authors measuring gravel bedload transport over long sampling periods and withlarge sampler openings (Wilcock, 2001; Bunte \& Abt, 2003).

\section{The ratio between bed load and suspended sediment yield}

Table 3 shows the ratio between bedload and suspended sediment load obtained for 12 stormflows which occurred between 2002 and 2011 in the Arvorezinha catchment. To estimate the bedload flux of these events, it was assumed that the ratio between the bedload transport rate and Q was

Table 3 Percent of bedload in terms of suspended load estimated for 12 stormflows in the Arvorezinha catchment.

\begin{tabular}{llccrrr}
\hline Date & $\begin{array}{l}\text { Peak flow } \\
\left(\mathrm{m}^{3} \mathrm{~s}^{-1}\right)\end{array}$ & $\begin{array}{l}\text { SSC } \\
\left(\mathrm{mg} \mathrm{L}^{-1}\right)\end{array}$ & $\begin{array}{l}\text { Load: } \\
\text { Bed }\end{array}$ & Suspended & Total & $\begin{array}{l}\text { Bedload/suspended } \\
\text { load (\%) }\end{array}$ \\
\hline 20-Aug-02 & 0.66 & 340 & 0.01 & 3.90 & 3.91 & 0.3 \\
22-Aug-02 & 1.44 & 270 & 0.29 & 1.61 & 1.90 & 18.2 \\
25-Oct-02 & 0.85 & 1080 & 0.03 & 8.85 & 8.88 & 0.3 \\
8-Jul-03 & 2.22 & 860 & 1.21 & 5.39 & 6.60 & 22.4 \\
15-Jul-03 & 1.36 & 760 & 0.36 & 10.90 & 11.26 & 3.3 \\
5-Feb-04 & 0.50 & 1240 & 0.00 & 3.51 & 3.51 & 0.0 \\
1-Jul-04 & 1.18 & 1210 & 0.14 & 13.44 & 13.58 & 1.0 \\
4-Oct-05 & 1.69 & 560 & 0.64 & 4.18 & 4.82 & 15.2 \\
11-Jan-07 & 0.93 & 710 & 0.03 & 5.81 & 5.84 & 0.40 \\
4-Jan-10 & 5.15 & 770 & 81.00 & 128.00 & 209.00 & 63.3 \\
22-Apr-11 & 1.80 & 660 & 0.80 & 8.40 & 9.20 & 9.5 \\
11-May-11 & 0.45 & 530 & 0.00 & 1.25 & 1.25 & 0.1 \\
\hline
\end{tabular}




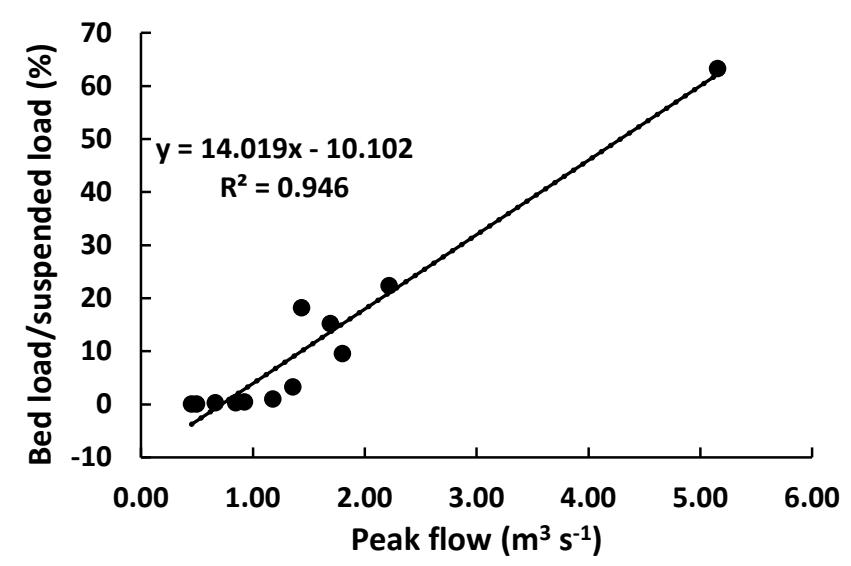

Fig. 5 Relation between peak flow and percent bedload in terms of suspended load.

stable for the period prior to and following the date on which this was determined. The ratio bedload/suspended load was variable for each of the 12 stormflows (minimum $<1 \%$ and maximum $60 \%$ ). Mean and median values for the 12 stormflows were $11 \%$ and $2 \%$, respectively. The variation of the bedload/suspended load ratio was associated with variable peak flow (Fig. 4). In other words, the greater the peak flow, the higher the ratio between bedload/suspended load. The mean and median values are close to that predicted using the Maddock classification (Lane \& Borland, 1951).

Evaluations of the relationship between bedload/suspended load for the Arvorezinha catchment showed a predominance of transport in suspension over bedload transport (Table 3). A high degree of inter-event variability in the ratio bedload/suspended load was also found, explained primarily by the variability in the peak flow (Fig. 5). Minella et al. (2008), utilizing the fingerprinting technique, found that the main sources of suspended load for the Arvorezinha catchment were fields $(62 \%-54 \%)$, unmetalled roads $(36 \%-24 \%)$ and channel $(2 \%-22 \%)$. These results shown that the main source of sediments transported in the stream channel originate from outside of the channel. In addition, the relationship between Q and SSC for Arvorezinha catchment demonstrates a complex temporal pattern during hydrologic events (Minella et al. 2011). The clockwise loop hysteresis pattern is predominant, indicating that the SSC peak occurred before the $Q$ peak which represents rapid mobilization and transference of sediments from unmetalled roads and fields to the stream channel.

When hydraulic streamflow conditions have enough energy $\left(\mathrm{Q}>0.40 \mathrm{~m}^{3} \mathrm{~s}^{-1}\right)$, there is bedload transport of the sediments retained in the pools. For high magnitude events (recurrence time greater than 10 years), when the streamflow height exceeds bankful, there can be movement of large diameter sediment $\left(\mathrm{D}_{50}>4.0 \mathrm{~mm}\right)$.

High magnitude stormflows that occur when the soil is saturated and there is little surface cover (such as during spring tilling) can provoke elevated rates of erosion $\left(>200 \mathrm{t} \mathrm{km}^{2}\right.$ year-1; Merten et al., 2010). During these conditions, gullies form that conduct a large quantity of sediment (clay, silt, sand and gravel) to the stream. Because the stream bed is quite stable, the sediments which originate in the stream are due to the erosive processes acting on the banks. The boulders and cobbles found in the channel are formed by the weathering process as the basalt bedrock is exposed and altered by the continuous streamflow. These materials, in turn, are moved only during exceptional stormflows when the hydraulic conditions possess much of energy, as discussed.

Although the average and the median that represent the bedload/suspended load ratio of the 12 stormflows are comparable with the Maddock classification estimation, it is important to consider that this procedure is only valid when there is a time series of events. In the case of the Arvorezinha catchment, the bedload yield for events that generated Q $>40 \mathrm{~m}^{3} \mathrm{~s}^{-1}$ the proportion of bedload/suspended load can be estimated by the relationship shown in Fig. 3. For other locations 
with step-pool streams where the slope, Q and sediment grain size are similar, results can probably be extrapolated, though it would be beneficial to expand the studies done on the Arvorezinha catchment to other similar streams.

By understanding the dynamics of sediment transport in the Arvorezinha catchment, we can see that a reduction in sediment transfer from the fields and unmetalled roads could significantly reduce the sediment load and its conveyance downstream with positive consequences for the hydroelectric dams and water quality. Soil conservation practices aimed at reducing sediment yield have been employed in these areas, with positive results in reducing sediment yield (Merten et al., 2010).

\section{CONCLUSIONS}

This study, which evaluated the bedload transport rate and the percent of bedload in terms of measured suspended load in a step-pool stream representative of the conditions on the basalt scarps of southern Brazil, concludes that:

(1) The variation in the bedload transport rate was adequately described by the variation in streamflow $>0.4 \mathrm{~m}^{3} \mathrm{~s}^{-1}$ by adjusting using a potential function with a power of 4 .

(2) Bedload transport for streamflow between $0.4 \mathrm{~m}^{3} \mathrm{~s}^{-1}$ and $1 \mathrm{~m}^{3} \mathrm{~s}^{-1}$ was selective for sediments smaller than those found on the surface and subsurface of the stream bed.

(3) The relation between the bedload/suspended sediment load showed great variation between the 12 stormflows studied where this variation was associated with the peak flow.

Acknowledgements Thanks to Sandro T. Gomes, Ademir Giongo and Rosália B. Cunha for their help with field and laboratory work, to SINDITABACO for their financial support of this research and to Elena Metcalf for her help with this manuscript.

\section{REFERENCES}

ANEEL Brazilian Energy Agency (2014).Brazilian Hydroelectric Reservoir Inventory Available from http://www.aneel.gov.br/aplicacoes/atlas/energia_hidraulica/4_6.htm (April, 2014).

Bunte, K. \& Abt, S. R. (2001) Sampling surface and subsurface particles-size distribution in wadable gravel-and cobble-bed streams for analysis in sediment transport, hydraulic, and streambed monitoring. Gen. Tech. Rep. RMSR-GTR-74.

Bunte, K. \& Abt, S. R. (2003) Sampler size and sampling time bed load transport rates and particle size measured with bed load traps in gravel-bed streams. In: Erosion and Sediment Transport Measurement in Rivers: Technological and Methodological Advances (ed. by J. Bogen, T. Fergus \& D. E. Walling), 12-133. IAHS Publ. 283.

Cantalice, J. R., et al. (2014) Relationship between bedload and suspended sediment in the sand-bed Exu River, in the semi-arid region of Brazil. Hydrological Sciences Journal doi: 10.1080/02626667.2013.839875.

Carvalho, N. O., et al. (2000) Guia de Práticas Sedimentometricas. ANEEL (in Portuguese).

Curran, J. C. (2007) Step-pool formation models and associated step spacing. Earth Surface Processes and Landform 32, $1611-1627$.

Diplas, P., et al. (2008) Sediment transport measurements. In: Sedimentation Engineering - Process, Measurements Modelling and Practice (ed. M. H Garcia), 307-309. ASCE Manual and Report on Engineering Practice No 110.

Edwards, T. E. \& Glysson, G. D. (1999) Field methods for measurement of fluvial sediment. US Geological Survey Techniques of Water Resources Investigations, Book 3. US Geological Survey.

Garcia, M. H. (2008) Sediment transport and morphodynamics. In: Sedimentation Engineering - Process, Measurements, Modelling and Practice, (ed. M. H Garcia), 21-146. ASCE Manual and Report on Engineering Practice No 110.

Garde, R. J. \& Ranga Raju, K. G. (1997) Mechanics of Sediment Transportation and Alluvial Stream Problems. Wiley Eastern Ltd.

Jackson, W. L. \& Beschta, R. L. (1982) A model of two-phased bedload transport in Oregon coast range stream. Earth Surface Processes and Landform 7, 517-527.

Lane, E. W. \& Borland, W. M. (1951) Estimating bed load. Transactions American Geophysical Union 32(1), 121-123.

Lenzi, M. A., Mao, L. \& Comiti, F. (2003) Interannual variation of suspended sediment load and sediment yield in an alpine catchment. Hydrological Sciences 48(6), 889-915.

Lisle, T. E. (1995) Particle size variation between bedload material in natural gravel bed channels. Water Resources Research $31,1107-1118$.

Merten, G. H., et al. (2010) The effects of soil conservation on sediment yield and sediment source dynamics in a watershed in southern Brazil. In: Sediment Dynamics for a Changing Future. (ed. by K. Banasik, A. J. Horowitz, P. N. Owens, M. Stone \& D. E. Walling), 59-67. IAHS Publ. 337.

Minella, J. P. G., Walling, D. \& Merten, G. H. (2008) Combining sediment source tracing techniques with traditional monitoring to assess the impact of improved land management on catchment sediment yields. J. Hydrology 348, 546-563. 
Minella, J. P. G.; Merten, G. H. \& Magnogo, P. F. (2011) Qualitative and quantitative analysis of hysteresis between sediment concentration and flow rate during hydrologic events. Revista Brasileira de Engenharia Agricola e Ambiental 15(12), 1306-1313 (in Portuguese).

Pitlick, J., et al. (2008) Relation between flow, surface-layer armoring and sediment transport in gravel-bed rivers. Earth Surface Processes Landforms 33, 1192-1209.

Walling, D. E. \& Collins, A. L. (2000) Integrated Assessment of Catchment Sediment Budgets: A Technical Manual. University of Exeter, UK.

Vanoni, V. A. (1975) Sedimentation Engineering, ASCE Manual and Report on Engineering Practice No.54.

Wathen, S. J., et al. (1995) Unequal mobility of gravel and sand and weakly bimodal river sediments. Water Resources Research 31(8), 2087-2096.

Whittaker, J. G. (1987) Sediment transport in step-pool streams In: Sediment Transport in Gravel-Bed Rivers (ed. by C. R. Thorne, J. C. Bathurst \& R. D. Hey), 545-579. John Wiley \& Son, Chichester.

Wilcock, R. P. (2001) Toward a practical method for estimating sediment transport rates in gravel-bed rivers. Earth Surface Processes Landforms 26, 1395-1408.

Wilcock, R. P., Pitlick, J. \& Cui, Y. (2009) Sediment transport primer estimating bed-material transport in gravel-bed-rivers. USDA General Technical Report 226. 